\title{
Assessment of housing affordability problem in Calabar Metropolis, Cross River State, Nigeria
}

\author{
${ }^{1}$ Ewa, E.E., ${ }^{2}$ Offiong, V.E., ${ }^{1}$ Njar, G. N. \& ${ }^{3}$ Ita, A. E. \\ 1. Dept. of Geography \& Environmental Science, University of Calabar, Nigeria \\ 2. Dept. of Urban \& Regional Planning, CRUTECH, Calabar, Nigeria \\ 3. Dept. of Environmental Health, College of Health Technology, Cross River State, Nigeria
}

\begin{abstract}
In this paper, housing affordability problems on residents in Calabar Metropolis, Cross River State, Nigeria is assessed. Systematic random method was used to administer one hundred and twenty copies of questionnaire to residents in three districts across the Metropolis. The study showed that majority of the tenants in Calabar Metropolis pay N2, 500 - N15, 000 monthly for their rented rooms. Majority of the tenants living in one bedroom and $2-3$ bed room flats were in the low and middle-income groups. The study reveals that people in Calabar spend substantial amount of their monthly income on housing. The study showed that residential housing problems varied significantly across different socio-economic groups ( $\leq \leq 0.05)$. The study also revealed that significant relationships existed between housing affordability and age, sex, income, educational attainment, marital status and occupation. The study suggested that agencies should be set up by the state government to monitor rental values charged by landlord/landladies across Calabar Metroplis as well as more housing schemes should be instituted by the government to reduce the monopoly of private land developers as well as meet the housing demands of its populace.
\end{abstract}

Keywords: Housing affordability, Socioeconomic groups, Calabar Metropolis, Tenants

\section{Introduction}

Housing is one of the three basic needs of mankind. After the provision of food, it is the most important factor for the physical survival of man. It has been shown that housing is one of the best indicators of a person's standard of living and place in the society. The concept of adequate housing implies more than just a dwelling, but includes all that is within the dwelling and the creation of a conducive environment in which people live and grow (Jiboye, 2009). However, in developing countries particularly Nigeria, the problem of housing is more pronounced than in the developed countries. Moreover, the shortage of housing in the urban areas is more pronounced and critical than in the rural areas. In Nigeria, the most pathetic feature of her society today is that a majority of its members are living in a state of hardship, while the remaining relatively insignificant minority is living in affluence. These skewed economic relations do not reflect the geographic spread of resource endowment; rather it is a product of classical greed, injustice and selfishness, which is beyond any economic principle. The rapid increase in the Calabar urban population in recent times has produced an enormous demand for shelter and tenure security. This growth has not been matched with simultaneous provision of housing. Thus, the significant rise in population has led to the acute shortage of dwelling units, resulting in overcrowding, high rents, poor urban living conditions, low infrastructure services, deteriorating environment, increasing poverty and rise in urban insecurity.

With the prohibitively expensive lands and high rents in the area amidst stagnating real incomes, it is not unusual for Calabar Metropolis to have huge numbers of families living in various types of unauthorized housing units with insecure tenure. Market values of residential lands in the area, for example, range from N100, 000 to as high as N500, 000 depending on the quality and location of the house, which is far beyond the incomes earned by the majority of the urban poor. But because people need to live in areas where economic opportunities, including informal activities, are present, it becomes expedient for most of them to occupy idle lands owned by government or the private sector. The proliferation of slums in the area is thus seen as a coping mechanism for urban dwellers with incomes that are too fragile to afford land ownership and expensive houses. Indeed, rising housing costs and house prices in Calabar Metropolis have called for concern as a result of the its associated housing stress. Affordable housing entails "housing of an adequate basic standard that provides reasonable access to work opportunities and community services and that is available at a cost which does not cause substantial hardship to the occupants.

Housing affordability is therefore compromised when households in the bottom $40 \%$ of income distribution spend more than $30 \%$ of their household income on housing, adjusted for household size. Slum areas are often blighted, overcrowded, and lacking in standard conveniences such as electricity, water, drainage and health services. These settlements are usually located in high-risk areas such as floodprone embankments, 
waterways and beside dumpsites with implications on their health. Housing problems across the Metropolis are also heightened with land developers having less interest to build medium and low cost housing. This is because the margin or profit earned is small. Private housing developers control most of the land in major towns and are interested to develop high cost or luxury housing for bigger margin or profit. The desire for high cost housing makes the housing cost beyond residents' affordable income. This indeed, creates housing problems to the urban poor with medium and lower income. According to Animashaun (2010), the problem of inadequate supply of residential housing and rising cost seems to be exceptionally serious in Calabar. In addition, the housing problems in Calabar Metropolis vary from inadequate quantity and quality of housing to the attendant impact on the psychological, social, environmental and cultural aspects of housing. Housing is capital-intensive. The cost of adequate housing is currently beyond the reach of most "Crossivarians". This, thus, brings in the financial dimension - the question of the affordability of housing. The challenge becomes not only to provide the houses but to make the houses affordable to the average "Crossivarian" worker. It is against the above background that the study assesses the impact of housing problem on residents in Calabar Metropolis, Cross River State, Nigeria.

\section{Materials and methods}

Study area

Calabar Metropolis is located between latitude $8^{0} 15^{\mathrm{I}} \mathrm{E}$ and $8^{0} 20^{\mathrm{I}} \mathrm{E}$, and longitude $4^{0} 45^{\mathrm{I}} \mathrm{N}$ and $5^{0} 30^{\mathrm{I}}$ N. The city lies on a peninsula formed by the Calabar River, Great Kwa River, the Cross River State estuary and the Atlantic Ocean. It has a sub-equatorial type of climate; the temperature is moderately high and not fluctuating greatly. The maritime position of Calabar exercises considerable ameliorating influence on its climate. The mean temperature is about $25^{\circ} \mathrm{C}$ with a range of about $8^{\circ} \mathrm{C}$. The annual rainfall exceeds 300 millimeters, most of which comes in the wet season from May to October. The relative humidity is high throughout the year, giving a mean annual figure of about $84 \%$. In Calabar, the inadequacy in shelter delivery system to cater for the urban population has led to an extensive development of squatter or unplanned settlements. The gap between the supply and demand for housing has been widening with time. The growing housing shortage is confirmed by overcrowding levels that are found in the area. The housing environment facilities in the area are deteriorating particularly with the increasing population.

\section{Data collection}

The study employed the descriptive cross sectional research design to investigate the effect of housing problems on residents in the metropolis across individuals from different socioeconomic backgrounds and ages of 18 and above. Data was collected from tenants residing in Calabar Metropolis. The systematic random method was used to administer one hundred and twenty copies of questionnaire to residents in three districts. This sampling technique was considered suitable given the characteristic layout of the districts; as some districts are well planned and numbered, while others are poorly planned and numbered.

\section{Method of data analysis}

Data obtained from the processes above were analysed using tables, simple frequency, charts, Pearson's correlation and One-Way analysis of variance (ANOVA). Housing affordability will be estimated as housing rent or cost divided by household income.

\section{Socioeconomic characteristics of respondents}

\section{Results}

Information on the sex of respondents shows that out of the respondents that constituted the survey, $56.7 \%$ were males, while $43.3 \%$ were females. This implies that males dominated the survey, which perhaps is expected as they are heads of families in their respective homes. Ages of depicts that $>40$ years group constituted $29.2 \%$ of respondents and was the highest number of respondents followed by $36-40$ years with $25 \%$ and then the $26-30$ years group which made up $18.3 \%$ of the respondents. The lowest number of respondents was within the 18 - 25 years group which constituted $10 \%$. From the pattern that emerged, it could be said that majority of employees are adults between the ages of 31 years and above. The marital status of respondents reveals that married couples constituted $50.8 \%$ of respondents and was the highest number of respondents followed by tenants who were unmarried with $40.8 \%$ and then marriages with setbacks which made up $8.3 \%$ of the respondents. This information therefore implies that majority of respondents $(59.1 \%)$ were tenants with families.

The educational qualifications of respondents reveals that $48.3 \%$ of the respondents had first degrees in respective fields of studies; and $24.2 \%$ were holders of NCE/OND, while only $15 \%$ had post-primary education. Interestingly, an infinitesimal proportion of the respondents had primary. This therefore implies that the entire respondents are literates and can provide precise and adequate information relating to the subject of investigation by the researchers. Information on the occupation of respondents is presented in Table 4.3. It has it 
that $32.5 \%$ of the respondents were civil servants in government departments and ministries; this was closely by those in teaching profession in both private and public schools $(23.3 \%)$ and then students in both state and federal government owned universities with $17.5 \%$. The occupations with the lowest percentage were company/factory work, trading and farming with $7.5 \%, 6.7 \%$ and $1.7 \%$ respectively. This implies that the workforce in the Metropolis and tenants is dominated by civil servants, teachers and students. The monthly of respondents indicates that $33.3 \%$ earned N41,000 - N70,000 monthly; $26.7 \%$ went home every month with N20,000 - N40,000 and 24.2\% earned monthly N71,000 - N100,000, while monthly income $>$ N100,000 was the lowest earned by the respondents with only 5\%. This reveals that monthly income range of N20, $000-$ $\mathrm{N} 100,000$ is earned by majority of the tenants across the metropolis.

\section{Housing type}

Figure 1 gives vital information on the housing type or dwelling units of respondents. It shows that single rooms constituted $40 \%$ of the dwelling units lived by respondents and was the highest followed by one bedroom flat with $26.7 \%$ and then $2-3$ bedrooms flat which made up $25 \%$ of the respondents. The lowest housing unit rented was within duplex which constituted $8.3 \%$. This indicates that duplex is rarely rented probably due to its cost, the commonly rented apartment is a single room house followed by one bedroom flat.

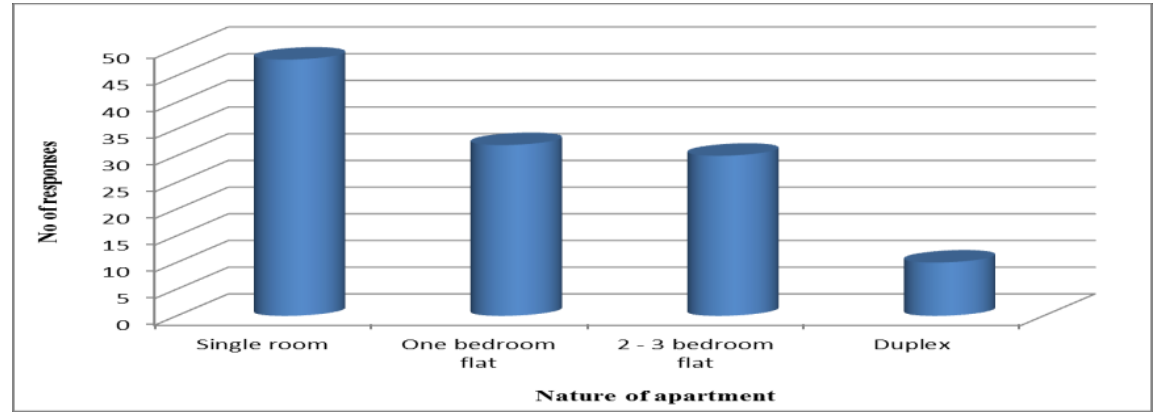

Fig 1: Nature of respondents' dwelling unit

\section{Housing cost/rental amount}

Information on the amount paid to rent a room or dwelling units across the metropolis is presented in Table 1. It shows that $34.2 \%$ of the respondents paid N2, 500 - N5, 000 monthly for their rented rooms; and $29.2 \%$ spent N11, 000 - N15, 000 monthly to maintain their tenancy as well as accommodate themselves, wives and loved ones as the case may be, while $15 \%$ of the respondents paid N1, 000 - N2, 000 and N6, 000 - N10, 000 for houses across the metropolis. The lowest amount paid by the respondents' surveyed for houses was $>\mathrm{N} 15,000$. This amount and the type of house can be afforded by the rich. The interesting observation was that majority of the tenants living in one bedroom and $2-3$ bed room flats were in the low and middle-income groups. But as a result of taste and the desire to live in quality rooms spend a lot to secure and maintain them. This indicates people in Calabar spend substantial amount of their monthly income on housing.

Table 1: Rental amount
\begin{tabular}{|l|c|c|}
\hline House rent & Frequency & Percent \\
\hline N1,000 - N2,000 & 18 & 15.0 \\
N2,500 - N5,000 & 41 & 34.2 \\
N6,000 - N10,000 & 18 & 15.0 \\
N11,000 - N15,000 & 35 & 29.2 \\
>N15,000 & 8 & 6.7 \\
Total & 120 & 100.0 \\
\hline
\end{tabular}

\section{Residents' level of satisfaction}

Respondents were asked to state their satisfaction level with their respective dwelling units. The information on Table 2 indicates that $66.7 \%$ of the respondents were to some extend satisfied with their rented apartment, while $33.3 \%$ of the respondents were not satisfied with their place of residence and housing. This group of tenants asserted that the cost of housing and their monthly income undermine their decision, which they would have liked to live in a room(s) where everything is provided, such as water, separate kitchen and toilet amongst other necessities. Majority of the tenants with this wishes live in a single and one bedroom flats. 
Table 2: Resident's satisfaction of housing

\begin{tabular}{|c|c|c|}
\hline Options & Frequency & Percent \\
\hline Very satisfied & 13 & 10.8 \\
Satisfied & 22 & 18.3 \\
Fairly satisfied & 45 & 37.5 \\
Not satisfied & 40 & 33.3 \\
Total & 120 & 100.0 \\
\hline
\end{tabular}

\section{Cause of housing problem}

Figure 2 below identifies increase in urban population in recent time, the lack of sufficient low density housing units owned by the government and high cost of building materials across the metropolis as the major causes of housing affordability problem. This is obvious as the population of Calabar has risen in the past decade due to its serene environment as well as the making of the area as the flagship of tourism in the country. These attributes have pushed migrants both from the rural and neigbouring states and countries to the state in search of job and pleasure. The increase in urban population without a corresponding provision of housing units has exacerbated housing problems in the area, with landlords and landladies holding tight to the opportunity.

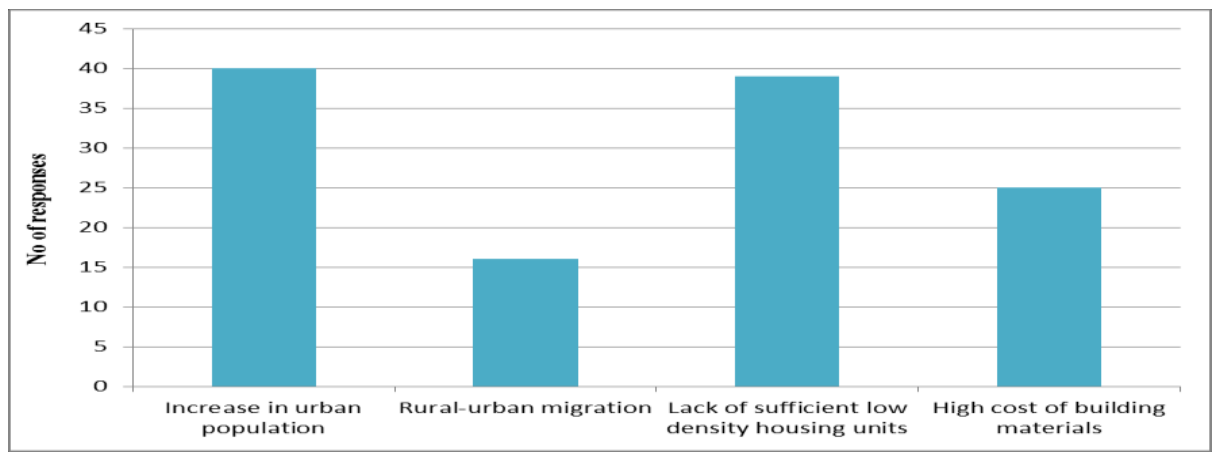

Fig 2: Housing problems

\section{Problems of housing shortage}

The problems associated with the insufficient provision of housing are presented in Table 3. It indicates that increase in rental value/cost (35\%), increase in housing demand (27.5\%) and issues of overcrowding (25\%) were the aftermaths of housing shortage in the Calabar urban space. This is so as the insufficient distribution of housing units have resulted in landlord-tenants strife as a result of the number of persons allowed in a room. Another noticeable problem is the gradual establishment of slum or squatter settlement at the urban fringe, which is basically dominated by individuals who cannot afford house rent.

Table 3: Problems of insufficient housing

\begin{tabular}{|l|c|c|}
\hline Options & Frequency & Percent \\
\hline Increase in rental value & 42 & 35.0 \\
Establishment of slums & 15 & 12.5 \\
Increase in housing demand & 33 & 27.5 \\
Issues of overcrowding & 30 & 25.0 \\
Total & 120 & 100.0 \\
\hline
\end{tabular}

Analysis of residential housing problems across different socio-economic groups

The researchers sought to find out whether residential housing problems vary significantly across different socio-economic. This hypothesis was tested using One-Way Anova (ANOVA). The result obtained is depicted in Table 4. The F-ratio values $22.480-36.650$ were significant at $5 \%$ level of significance. That is, the probability values $(0.000)$ are less than the significance level $(5 \%)$. This therefore implies that residential housing problems vary significantly across different socio-economic groups. 
Table 4: Summary of ANOVA results

\begin{tabular}{|l|c|c|c|}
\hline Variables & F-ratio & df & Sig value \\
\hline Age & $22.396^{*}$ & $4 / 115$ & 0.000 \\
\hline Income & $36.650^{*}$ & $"$ & $"$ \\
\hline Education & $22.480^{*}$ & $"$ & $"$ \\
\hline Occupation & $23.960^{*}$ & $6 / 113$ & $"$ \\
\hline
\end{tabular}

*Difference amongst means is significant at the 0.05 level (2-tailed).

Source: SPSS Window Output Version 17.0

Analysis of relationship between housing affordability and housing costs, age, sex, income, educational attainment, marital status and occupation

Also, the researchers sought to find out whether there are significant relationships between housing affordability and age, sex, income, educational attainment, marital status and occupation. The hypothesis was analysed using Pearson's correlation. Housing affordability ratio was computed using the formula given by Ndubueze (2009) as:

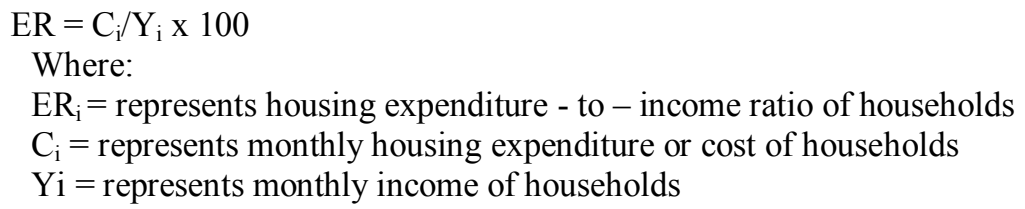

This model was used to situate $15 \%$ of gross household income as a benchmark for housing affordability for households in the area of study. From the obtained result, housing affordability of households was coded as 1 if the respondent was able to afford their housing and 0 if the respondent was not unable to afford their housing due to a housing cost burden. The results obtained are presented in Tables 5.1 to 5.2. The Pearson's correlation reveals that significant and positive association existed between housing affordability and age, marital status, occupation and education of respondents with $r$-Values ranging from $0.26-0.51$ (Table 5.1). Furthermore, the result of multiple correlation analysis reveals that there is a high, positive and significant relationship between the predictor variables (age, sex, income, educational attainment, marital status and occupation) and the criterion variable (housing affordability). It also reveals that 54.9 per cent of the variance in residents' housing affordability is attributed to the predictor variables (5.2). This implies that there are significant relationships between housing affordability and age, sex, income, educational attainment, marital status and occupation.

Table 5.1: Summary of Pearson's correlations

\begin{tabular}{|l|c|c|c|c|c|c|c|}
\hline & Housing affordability & Age & Marital & Sex & Education & Occupation & Monthly \\
\hline \multirow{3}{*}{ Sig. (2-tailed) } & 1 & $.260^{* *}$ & $.509^{* *}$ & -.115 & $.531^{* *}$ & $.410^{* *}$ & -.086 \\
$\mathrm{~N}$ & & .004 & .000 & .212 & .000 & .000 & .352 \\
\hline
\end{tabular}

**. Correlation is significant at the 0.01 level (2-tailed).

Table 5.2: Summary result of multiple correlation

\begin{tabular}{|l|c|c|c|c|}
\hline Model & $\mathrm{R}$ & $\mathrm{R}$ Square & Adjusted R Square & Std. Error of the Estimate \\
\hline & $.741^{\mathrm{a}^{*}}$ & .549 & .525 & 3.6440 \\
\hline
\end{tabular}

Predictors: (Constant), Education, Occupation, Sex, Marital, Age, Monthly

*Correlation is significant at the 0.01 level (2-tailed).

Source: SPSS Window Output Version 17.0

\section{Discussion of result}

The study shows that males dominate the survey, which perhaps is expected as they are heads of families in their respective homes. The ages of respondents reveal that majority of tenants are adults between the ages of 31 years and above. Information on the occupation shows that majority of the workforce in Calabar Metropolis and tenants are dominated by civil servants, teachers and students. The study indicates that duplex is rarely rented probably due to its cost, and that the commonly rented apartment is a single room house followed by one bedroom flat. The analysed result indicates that majority of the tenants in Calabar Metropolis pay N2, $500-\mathrm{N} 15,000$ monthly for their rented rooms, and the lowest amount paid for houses is $>$ N15, 000. The interesting observation was that majority of the tenants living in one bedroom and $2-3$ bed room flats were in the low and middle-income groups. But as a result of taste and the desire to live in quality rooms tenants spend a 
lot to secure and maintain them. This indicates that people in Calabar spend substantial amount of their monthly income on housing.

In a related study, Akeju (2009) identified infrastructure as another major challenge to providing affordable housing is the lack of primary infrastructure such as roads, water, electricity etc., which accounts for about 30 percent of housing costs. In most cases developers have to provide the infrastructure which invariably increases the cost of the houses they produce thus making such houses unaffordable. The study reveals that majority of the tenants are to some extent satisfied with their rented apartment, while $33.3 \%$ are not satisfied with their place of residence and housing. This group of tenants asserted that the cost of housing and their monthly income undermine their decision, which they would have liked to live in a room(s) where everything is provided, such as water, separate kitchen and toilet amongst other necessities. Majority of the tenants with this wishes live in a single and one bedroom flats. Increase in urban population in recent time, the lack of sufficient low density housing units owned by the government and high cost of building materials across the metropolis are identified as the major causes of housing affordability problem.

This finding is consistent with those of Olotuah and Ajenifujah (2009) when they pointed out that urbanisation and industrialisation are the main factors that pushed up the demand of housing in the urban areas. They argued further that housing problems can also arise when the developers in the urban areas, have less interested to build medium and low cost housing. This is because the margin or profit earned is small. Also, Akeju (2007) noted that high cost of building materials as one of the challenges of housing provision in Nigeria. This is obvious as the population of Calabar has risen in the past decade due to its serene environment as well as the making of the area as the flagship of tourism in the country. These attributes have pushed migrants both from the rural and neigbouring states and countries to the state in search of job and pleasure. The increase in urban population without a corresponding provision of housing units has exacerbated housing problems in the area, with landlords and landladies holding tight to the opportunity.

Furthermore, the study reveals that increase in rental value/cost, increase in housing demand and issues of overcrowding are the aftermaths of housing shortage in the Calabar urban space. This is so as the insufficient distribution of housing units have resulted in landlord-tenants strife as a result of the number of persons allowed in a room. This also agrees with the finding of Seleki (2001) that the inadequacy in shelter delivery system in Tanzania to cater for the urban population has led to an extensive development of squatter or unplanned settlements; and that the growing housing shortage is confirmed by overcrowding levels that are found in urban areas. The study identifies sickness and injuries as the commonest health problems associated with poor housing conditions. It is not out of place to say that most of the houses in Calabar Metropolis irrespective of the type lack essential facilities such as inbuilt toilet and kitchen, tenants sometimes are mandated to share either toilet or kitchen or both. In some places, the landlord has used all the available space thereby compromising the health of his/her tenants. Also, some of the materials used for the building are of low quality causing injuries to tenants therein such as building collapse or partial collapse.

Matte and Jacobs (2000); Krieger and Higgins (2002) report that structural defects can lead to injuries in and of themselves they can also help to facilitate other housing problems that can pose risk to human health. Homes with structural defects may lead to physical injuries. They further noted that poor quality housing could lead to pest infestations which include infestations of both rodents and insects and can be facilitated by structural defects that allow entrance. Pest infestations pose a number of health risks including multiple communicable diseases. The analysis indicates that residents' satisfaction with public housing varies across different socio-economic groups. This is evident as the housing demand and quality of tenants vary in relation to their socioeconomic status in the society. People with higher income go for high cost houses and vice versa. Also, it shows that residential housing problems across different socio-economic groups vary significantly. This is evident as high cost houses are usually well planned and built than low cost houses which most times are hurriedly built with inferior materials, thereby constituting health challenges to tenants therein. The study further reveals that significant relationships exists between housing affordability and age, sex, income, educational attainment, marital status and occupation. This is evident as residents' socioeconomic background determines their ability to pay for housing irrespective of the rental values, as the higher one's income, the more will such a person be ready to pay for housing and vice versa.

\section{Conclusion}

The study shows that there is problem of housing affordability in the area as tenants in Calabar Metropolis spend substantial amount of their monthly income on housing. Despite, the charges or cost to rent a room, most of the houses are not well equipped. Some of the tenants are not satisfied with their place of residence and housing; as the cost of housing and their monthly income undermine their decision. The insufficient provision of housing across the metropolis as well as the high cost of housing results in overcrowding. Housing demand and quality vary in relation to tenant's socioeconomic status in the society, as tenants with higher income go for high cost houses and vice versa. Housing affordability across the metropolis 
is a function of age, sex, income, educational attainment, marital status and occupation. Increase in urban population in recent time, the lack of sufficient low density housing units owned by the government and high cost of building materials across the metropolis are identified as the major causes of housing affordability problem. Based on the findings of this study, the study suggests that agencies should be set up by the state government to monitor rental values charged by landlord/landladies across Calabar Metroplis as well as more housing schemes should be instituted by the government to reduce the monopoly of private land developers as well as meet the housing demands of its populace.

\section{References}

[1]. Akeju, A. A. (2007) Challenges to providing affordable housing in Nigeria. Being a Paper Presented at the 2nd Emerging Urban Africa International Conference on Housing Finance in Nigeria, Held at Sehu Yar'adua Center Abuja, October 17-19, 2007

[2]. Animashaun, I. A. (2010) Provision of residential housing and environmental development in Calabar: Policy Contradictions. Retrieved from: http://www.readperiodicals.com/201001/2307422931.html

[3]. Jiboye, A. D. (2009) Evaluating tenants' satisfaction with public housing in Lagos, Nigeria. Town Planning and Architecture, 33(4): $239-247$.

[4]. Krieger, J. and Higgins, D. (2002) Housing and health: time again for public health action. Am J. Public Health, $92: 758-768$.

[5]. Matte, T. D. and Jacobs, D. E. (2000) Housing and health--current issues and implications for research and programs. J. Urban Health, 77(1):7-25.

[6]. Ndubueze O (2009). Urban housing affordability and the housing policy dilemmas in Nigeria. Unpublished Ph.D, University of Birmingham. Available at: http://etheses.bham.ac.uk/298/

[7]. Olotuah, A.O. \& Ajenifujah A. O. (2009) Architectural Education and Housing Provision in Nigeria" In CEBE Transactions. Online Journal of Centre for Education in the Built Environment, Cardiff University, UK, 6 (1)

[8]. Seleki, B. A. (2001) Urban housing problems in Tanzania some possible policy interventions. 